\title{
Nicolas Di Méo, Le Cosmopolitisme dans la littérature française
}

\section{Laura Brignoli}

\section{Q OpenEdition}

1 Journals

\section{Edizione digitale}

URL: http://journals.openedition.org/studifrancesi/6411

DOI: 10.4000/studifrancesi.6411

ISSN: 2421-5856

\section{Editore}

Rosenberg \& Sellier

\section{Edizione cartacea}

Data di pubblicazione: 1 novembre 2010

Paginazione: 583-584

ISSN: 0039-2944

\section{Notizia bibliografica digitale}

Laura Brignoli, «Nicolas Di Méo, Le Cosmopolitisme dans la littérature française», Studi Francesi [Online], 162 (LIV | III) | 2010, online dal 30 novembre 2015, consultato il 09 janvier 2021. URL: http:// journals.openedition.org/studifrancesi/6411; DOI: https://doi.org/10.4000/studifrancesi.6411

Questo documento è stato generato automaticamente il 9 janvier 2021.

\section{(c) (i) (9)}

Studi Francesi è distribuita con Licenza Creative Commons Attribuzione - Non commerciale - Non opere derivate 4.0 Internazionale. 


\title{
Nicolas Di Méo, Le Cosmopolitisme dans la littérature française
}

\author{
Laura Brignoli
}

\section{NOTIZIA}

NICOLAS DI MÉO, Le Cosmopolitisme dans la littérature française, Genève, Droz, 2009, pp. 351.

La prima metà del secolo scorso è stata oggetto di approfonditi studi sull'articolazione fra letteratura e ideologie, ma mancava ancora un quadro d'insieme su un'idea che percorre in modo trasversale il campo letterario visto da una prospettiva storicoideologica. Sulla complessità del cosmopolitismo analizzato senza ignorarne le sfumature Di Méo non manca di insistere, mostrando evoluzioni e differenze non solo fra un periodo e l'altro, ma spesso all'interno dell'opera di ogni singolo autore. Appare così un mosaico complesso nel quale tuttavia l'idea in sé col passare degli anni perde le connotazioni negative cui era associata sul finire del XIX secolo, quando sul concetto di nazione e di appartenenza alla "razza" poggiava il senso dell'identità individuale e sociale in modo così pervasivo da essere raramente messo in discussione. Non stupisce che autori quali Bourget, Barrès, Morand, Drieu La Rochelle riconoscano nella fedeltà ai costumi tradizionali l'unica garanzia di ordine e stabilità, anche se per quest'ultimo il determinismo biologico sarà presente solo alla fine della sua produzione. Ma spesso l'ostilità al cosmopolitismo inteso come fusione di razze supera le barriere destra/ sinistra, per esempio laddove l'anticapitalismo si lega all'antisemitismo. Le scelte dell'A. all'interno della produzione letteraria del periodo sono funzionali all'emergenza della connessione fra ibridazione e decadenza, cosmopolitismo e amoralità, desiderio d'ordine e fuga dagli schemi culturali imposti dalla società. L'attenzione alle sfumature permette tuttavia di segnalarne la complessità pur all'interno di una temperie culturale piuttosto uniforme che, fra le due guerre, vede prevalere l'associazione fra modernità, cosmopolitismo e standardizzazione. 
2 Si critica il cosmopolitismo laddove lo si confonde con un meticciato di massa che induce alla perdita dei tratti identitari e all'abbandono dei costumi e dei valori tradizionali. Ma l'A. mostra come le sue connotazioni cambino qualora lo si consideri elitariamente (Larbaud) come un'opportunità e non un pericolo (Cendrars), come una delle cause della supremazia europea (Valéry), o quando si ritiene che la Francia sia la migliore rappresentante di un ideale di armonia fra i popoli (Giraudoux, Benda). Così, poco a poco, il cosmopolitismo esprime un ritorno alle fonti della vera identità europea, fra ideale classico e messaggio di tolleranza cristiana (Rolland). L'imperatore Adriano (Yourcenar) segna la fine dell'evoluzione di un ideale universalistico ancora capace, nel 1950, di ordinare il mondo. L'A. ha scelto di relegare in nota la dibattuta questione dell'antisemitismo yourcenariano interpretando per giunta la scelta di rappresentare un potere autoritario forte come «une tentative de réhumanisation de l'autorité» (p. 315).

3 La conclusione di uno studio che ha mostrato i legami del cosmopolitismo con le nozioni di decadenza e progresso, identità e differenza, armonia e ordine, non è priva di spunti da sviluppare per estendere l'analisi all'arco temporale successivo. 